\title{
Collective Efficiency and Collective Failure: The Response of the Sialkot Surgical Instrument Cluster to Global Quality Pressures
}

\begin{abstract}
KHALID NADVI *
Institute of Development Studies, Brighton, $U K$

Summary. - One of Pakistan's rare examples of consistent export success has been the Sialkot stainless steel surgical instrument cluster. This cluster, consisting mainly of small and medium enterprises (SMEs), has as its main markets the United States and Western Europe. In recent years, access to these markets has become contingent on meeting international quality assurance standards. The hypothesis explored in this paper is that meeting such standards requires greater local cooperation, both among producers as well as between producers and their suppliers and subcontractors. The study draws on quantitative and qualitative data to examine how inter-firm ties, both vertical and horizontal, have changed. The evidence suggests that joint action has increased, but that there remain significant areas of collective failure. Thus, the quality assurance pressures mark a possible turning point for the cluster, raising questions as to whether local sources of competitiveness, captured in the collective efficiency concept, can continue to provide the basis for export success. It also leads directly to an evaluation of the cluster's growth trajectory. (c) 1999 Elsevier Science Ltd. All rights reserved.
\end{abstract}

\section{INTRODUCTION}

The one truth about global competition is that it is constantly changing. As Kaplinsky (1998) has noted, competing in ever-more demanding world markets requires producers to run just in order to keep up. The criteria that define best practice in manufacturing are continually developing, reflecting the constant pace of upgrading in both product and process technologies. In recent years, international standards that verify compliance on a range of issues, including quality assurance, environmental standards, labor norms and even social ethics, have gained importance in global competition. ${ }^{1}$

Standards provide consumers with a basis for making informed consumption decisions, and manufacturers with a benchmark of best practice. For many producers and service providers, from the North and the South, compliance with international standards can add a competitive edge. It may also be necessary to retain access in key niche markets. There is now a growing literature which examines standards as non- tariff barriers to trade (Stephenson, 1997; EC, 1997), especially with regards to labor (Sengenberger and Campbell, 1994; OECD, 1996, 1995; Krueger, 1996; Maskus, 1997; White, 1996; ILO, 1997; Grootaert and Kanbur, 1995) and environmental standards (Dion, Lanoie and Laplante, 1997; Anderson, 1996).

This paper examines how clustered producers have responded to the new standards of quality assurance, focusing in particular on inter-firm

\footnotetext{
* Financial support from the Department for International Development, London is gratefully acknowledged. The author thanks the Surgical Instrument Manufacturers Association in Sialkot, Pakistan for its support, and the various respondents interviewed in Sialkot for their valuable time. The excellent research assistance provided by Waheed Murad in Sialkot is highly appreciated. The author benefited from discussions and comments on earlier drafts provided by Tilman Altenburg, John Humphrey, Peter Knorringa, Roberta Rabellotti and Hubert Schmitz. The author is solely responsible for the views expressed in this paper.
} 
relations and production organization in the cluster of surgical instrument producers in Sialkot, Pakistan. This cluster is an established player in its global market but struggling to meet the international quality assurance standards.

Small and medium enterprises (SMEs) have made Sialkot Pakistan's leading center in per capita terms for manufactured exports. Sialkot's SMEs are organized around sector specific clusters producing sports goods, leather garments and stainless steel surgical instruments. The latter is the largest in employment terms. The 300 or so family-run manufacturing enterprises that form the core of the Sialkot surgical instrument cluster together exported over US\$100 million worth of instruments in 1992-93. The cluster's main market is the United States with $60 \%$ of total export sales. During the mid-1990s the Sialkot cluster faced a major crisis of quality assurance. This crisis provides a possible 'turning point' that could well determine the cluster's future growth path and its ability to remain globally competitive. ${ }^{2}$

In May 1994 the Food and Drug Administration (FDA) of the United States, the key regulatory body in the US health sector, restricted imports of Pakistani-made surgical instruments for failing to meet the internationally accepted quality assurance standards of Good Manufacturing Practices (GMP). This action had serious consequences for Sialkot's producers, especially those exporting predominantly to the United States. Consignments were stranded midway, orders cancelled, many firms and subcontractors ceased operation, and a large number of workers were laid off.

GMP standards are one measure of quality assurance. They are closely related to other internationally recognized quality assurance certifications, such as the ISO 9000 series, which certify that standardized and accountable quality control processes are used at each stage in a product's design, development, manufacture and distribution. In line with the emphasis on total quality-management (TQM), they provide a system of traceability, involving detailed verification of quality-dependent procedures through internal and independent audits, quality training of personnel and constant monitoring of quality performance measures. Implementing such standards requires changes in production organization and management practices. This has implications for the relationship producers have with suppliers and with other firms. The upgrading required necessitates a capacity to learn both at the level of the individual firm and in the relations between firms. In the cluster context, knowledge spillovers can facilitate such learning (Audretsch and Feldman, 1996). Moreover, cluster-wide bodies and real services centers can accelerate the dissemination of know-how among local producers (Brusco, 1992). Finally, compliance by local producers can enhance a cluster's overall quality standards, providing it with a highly marketable 'quality label'.

Conforming to international quality assurance standards can be a costly process, not only in terms of certification expenses but also in acquiring the know-how to implement the required changes. Furthermore, pressures to meet standards in one area can also be a precursor to complying with international standards requirements in other fields. For Sialkot's surgical instruments sector, continued access to premium markets in Western Europe and Japan is becoming conditional on achieving the ISO 9000 series of quality assurance standards. In addition, there are growing demands on the cluster to meet global concerns on child labor. Thus, the crisis of 1994 provided an indication of the new competitive challenges the Sialkot cluster would face in global markets.

The response to these pressures has been impressive. By late 1997 sales of surgical instruments from Sialkot were above the precrisis levels. Overall quality had also improved, with over 130 of the 300 manufacturers in the cluster certified by the FDA as conforming to GMP standards and two firms having obtained the coveted ISO 9002 quality assurance certificate. The evidence from the field was equally strong. Of the 60 firms surveyed in November 1997, 68\% reported rising sales levels since the crises. Over half the sample stated that employment levels had also gone up. Two-thirds were already GMP certified and $37 \%$ of the sample had begun the process of obtaining ISO 9002 certification. This is, by any measure, a remarkable and rapid turnaround. This paper seeks to explain how the turnaround was achieved. In particular, it explores whether collective efficiency advantages arising from clustering, especially joint action gains, were significant in the process of upgrading and learning required to meet such standards.

Elsewhere I have shown how the concept of collective efficiency can take us further in understanding the cluster's relative success as a global player in a niche product line (Nadvi, 
1999). Local producers have benefited from local external economies and have entered into various forms of joint action. Cheap labor has undoubtedly been important, but fails to explain why Sialkot became a leading export center. In making the argument on collective efficiency, the main focus has been on interfirm relations and the basis they provide for local sources of competitiveness.

This study takes the collective efficiency argument further by exploring how clustered producers respond to an exogenous crisis. This particular crisis of quality assurance raises questions about changes in the relationships within supply chains. Do they become closer, more collaborative and obligational, or do firms reduce the quality-related costs of monitoring by internalizing activities? As the crisis is cluster-wide, questions also arise on changes in horizontal collaboration and the role played by local institutions such as the trade association. The underlying concern is with the cluster's growth trajectory. This includes understanding how the structure of the cluster, and the production relations that characterize it, have changed as a consequence of the crisis.

The paper draws on qualitative and quantitative primary data collected in two survey rounds. ${ }^{3}$ The pre-crisis fieldwork, conducted in 1993-94, included a survey of 57 surgical instrument manufacturers and 72 subcontractors, alongside case studies and key informant interviews. The post-crisis survey, conducted in two stages, included qualitative evidence gathered from case study firms and key respondents in January 1997, followed by a detailed survey of 60 firms in November-December $1997 .{ }^{4}$

The discussion is structured as follows. The following section considers the links between quality assurance, upgrading and collective efficiency. Section 3 provides a brief overview of the Sialkot cluster, describing the quality assurance crisis and chronicling the events that subsequently took place. Section 4 shows how horizontal relationships have changed in response to the crisis. Section 5 turns to vertical ties, examining whether the crisis spurred joint action with local suppliers and subcontractors and external buyers. Section 6 tests the proposition that increased cooperation has had a positive impact on performance. The concluding section summarizes the evidence on collective efficiency and on collective failure, and discusses the implications for the future development of the Sialkot cluster.

\section{QUALITY ASSURANCE STANDARDS AND COLLECTIVE EFFICIENCY}

Quality assurance standards move the focus away from product to process quality. Traditionally, quality standards were based on product characteristics such as durability, reliability, conformance to specifications and safety. During the 1980s and 1990s however, concern began to shift toward the processes involved in production and a new category of standards began to emerge. For example, the ISO 9000 series of standards (which developed from British Standard BS5750) concentrate on the documentation of quality procedures, while the ISO14001 standard deals with the documentation of environmental procedures in production. The motivation for quality assurance standards emerged as a result of the desire of component and service users for high quality input produced at low costs. This was directly related to the changes in management practices and the adoption of total quality control procedures. Thus the issue was no longer of simply ensuring the quality of the end product, but also of being able to verify the quality control process that had been used, and the quality values that had been instilled, at each and every stage of production. Among other things, this has implications for the way production is organized, with "quality at source," "quality responsibility" and "total quality management" becoming key elements of a "total quality control" production organization.

For the surgical instruments sector, quality assurance is particularly significant given that the industry manufactures what the FDA terms "critical devices." The consequence of instrument failure can be extremely costly-lives can be at stake. In the West, malpractice litigation places a heavy penalty on failure by health providers. The latter require suppliers further down the health provision chain to comply with quality assurance norms. The traceability benefits, offered by a quality assurance procedure, ensure that faults can be located and responsibilities for failure clearly defined. It also implies that international quality standards have been met. For manufacturers meeting global quality assurance standards can potentially raise economic efficiency, provide a basis for benchmarking, and be an important tool in a firm's competitiveness strategies. Thus, in order to raise their share of the global surgical instrument market, Pakistani producers have to improve efficiency by cutting costs and raising 
productivity. They also have to raise quality and provide documented, verifiable and internationally accepted quality assurances to existing and potential buyers.

The required upgrading calls for changes in production organization and management practices within the firm and in their relationships within the supply chain. "Soft technologies" on organizational practices have to be absorbed. These include: detailed record keeping of each production batch flow through the various stages of production; adoption of process-specific quality accounting systems with systematic testing of materials and standards at key stages, and a restructuring of manufacturing to emphasize stock and quality control, as well as health and safety standards. This demands a change in management outlook and in the traditional "ways of doing." Most profoundly, it requires the inculcation of qualitydriven production values.

The FDA's actions were not directed at an individual firm but to the cluster as whole. All producers in Sialkot were deemed to have failed to comply with international standards. Individual responses by firms were unlikely to result in the compliance required. Assimilation of quality values and upgrading of practices had to be across the cluster.

The collective efficiency argument is of significance here: it suggests that the upgrading called for cannot be advanced by SMEs on their own. A collective response is needed. This is likely to generate cluster-wide gains. Collective efficiency is defined as having two aspects to it: external economies that clustered agents accrue by virtue of their location, and joint action benefits that arise from deliberate cooperation between local agents. I view external economies as the "passive" dimension of collective efficiency (Nadvi, 1996). The term passive describes the nature of ties required between local agents in order to obtain externality gains. In contrast, joint action is the "active" dimension of collective efficiency requiring deliberate and active cooperation. These two aspects can also be clearly linked; joint action by some agents can generate cluster-specific externality gains for others (Nadvi, 1996). It is the combination of these benefits, external economies and joint action gains, that provide a basis for enhanced competitiveness for clustered SMEs compared with similarly sized, yet dispersed, producers.

The collective efficiency model relates directly to the pressures raised by quality assurance standards. Upgrading on quality assurance requires upgrading of local supply chain linkages within the cluster. While quality assurance standards effectively lower transaction costs (Foss, 1996), achieving them requires the building of closer ties and greater information flows within the supply chain. This implies greater cooperation in vertical relations between producers and their various suppliers. Firms and suppliers both need to monitor production closely, keeping and sharing detailed information on production flows, source and reject rates at each and every stage of production. This suggests greater coordination within the supply chain, and openness on the part of suppliers for external monitoring by producers. These enhanced interactions, and their implicit focus on quality and qualitycritical stages of production, facilitate a wider set of technical discussions within the supply chain on quality and technical upgrading. Moreover, given the costs of such linkages, firms are potentially encouraged toward more obligational, as opposed to arms-length, ties (Sako, 1992). These changes clearly imply that clustered firms can no longer rely purely on the passive dimension of collective efficiency in order to compete in global markets. They need to focus increasingly on upgrading their supply chains, which requires joint action in local vertical ties.

Similarly, joint action in horizontal ties, through local multilateral institutions can assist this process of upgrading by facilitating the flow of technical information on standards and by assisting in managerial training. Local institutions can also play a potentially key function in defining and regulating local product standards, and thus in creating a reputational basis for the cluster's products. This provides a powerful example of what I refer to as "externalities of joint action" (Nadvi, 1996, 1999).

In so much as quality assurance standards are an emerging feature of demand-driven pressures within the new competition, they underline the link between market conditions and joint action. Competing in demand-led markets requires local clustered producers to go beyond the passive dimension of collective efficiency and engage in local cooperation both within vertical supply chain linkages and through horizontal collaboration within local institutions. Furthermore, where quality assurance pressures raise demands for new forms of knowledge on managerial organization and production best practices, upgrading requires 
learning. Learning ties, involving both interaction with external agents and through local feedback and demonstration, demand greater and more coordinated collaboration. To the extent that quality assurance standards pose new sets of questions and require new managerial know-how, external buyers can become an important conduits for such information. This clearly raises concerns of whether local sources of competitiveness within the cluster, captured in the collective efficiency notion, are sufficient to generate the basis for the cluster's continued ability to vie in global markets.

This paper puts forward the hypotheses that upgrading to meet global standards by clustered producers necessitates enhanced joint action in both vertical and horizontal ties. Moreover, it argues that such upgrading will have positive consequences on firm and cluster growth. Before turning to the empirical evaluation of this argument, however, the following section presents an overview of the cluster and the crisis.

\section{THE SIALKOT SURGICAL INSTRUMENT CLUSTER AND THE QUALITY ASSURANCE CRISIS}

\section{(a) Brief overview of the cluster}

The Sialkot surgical instrument cluster consists of a core of 300 producers, surrounded by a range of over 1,500 process specialized subcontractors, a further 1,000 ancillary, supply and support units as well as a number of support institutions. Among the latter are the Metal Industries Development Centre (MIDC) that provides technical services to local firms; the Surgical Instrument Manufacturer's Association (SIMA) which represents local producers; and, the Sialkot Dry Port Trust (SDPT) which has "brought the port to the cluster," providing customs handling, storage and transportation facilities. ${ }^{5}$

Over 2000 different types of surgical instruments are produced in Sialkot. These are themselves differentiated by market segment: high quality, reusable, operation theatre instruments and lower quality, disposable, floor instruments. The two segments are distinguished by the type of raw material, quality of workmanship, and end markets. Disposable instruments are produced from locally sourced, recycled, or scrap-based, stainless steel and exported primarily to the high volume US market. Since the mid-1980s demand for disposable instruments has risen in the US following concerns on the spread of infectious diseases through contaminated instruments and the rising costs of sterilization. Reusable operation theatre instruments are made from higher quality imported stainless steel, and are predominantly exported to Western Europe, particularly Germany where a number of the leading international surgical instrument manufacturers subcontract to Sialkot-based producers.

The cluster generates various agglomeration benefits for local producers. These include the presence of a wide range of specialist input and service providers who ensure competitive prices and facilitate the ability of local producers to compete in distant markets. Producers are not required to hold large stocks of input, and can call on the wide range of export-related service providers, from shipping agents to international couriers. The large presence of specialist subcontractors generates economies of scale and scope. The cluster also provides a concentration of skilled labor, the most frequently cited locational advantage. The labor market clears rapidly, facilitated by the easy availability of information within the cluster. In addition, the flow of technical and marketing information enhances prospects of technical development.

In addition to these "passive" gains of clustering, which lower costs and raise efficiency, there is evidence of local joint action. Firms collaborate with their local suppliers and subcontractors, particularly on issues of quality. Horizontal cooperation is less marked. Yet there are a number of local institutions, including the trade association, the chamber of commerce and the dry port, which reflect horizontal inter-firm cooperation. At the same time local rivalry is intense. Producers compete with each other in an environment where price, quality and reliability are essential factors for export success.

The Sialkot cluster is also highly differentiated. A small number of the cluster's original SMEs have grown into large firms and have developed close collaborative linkages and joint venture units with key external players, particularly leading international producers. There also many small enterprises that struggle to survive. This process of increasing internal differentiation, and the related intensity of the local competition, raises questions of the cluster's growth trajectory. Will price competition 
and cost cutting force the cluster down a "low road" (Sengenberger and Pyke, 1991)? Or is there the possibility of a "high road" where quality led developments encourage innovation, growth and rising real incomes?

\section{(b) The quality assurance crisis}

In the context of these questions, the quality assurance crisis of 1994 provides a potential turning point for the Sialkot surgical instrument cluster. Before turning to the discussion on how the cluster responded it is useful to map the events associated with the crisis.

Concerns regarding the quality of Sialkot's surgical instruments had begun to emerge during the latter half of the 1980s (Wiegersma, 1989; GEMCO, 1990). In 1989 the FDA temporarily restricted imports of Sialkot-made instruments on the grounds of unacceptable metal composition standards. Random tests revealed that the chromium content and hardness of recycled Pakistani stainless steel was below par, leading to a higher risk of rust and breakage. The concerns expressed by the FDA in 1989 were largely allayed by the early 1990s. A technical dialogue ensued between Sialkot's surgical instrument producers and the local steel re-rolling sector, resulting in gradual improvements in the quality of the locally produced scrap-based stainless steel.

The FDA's action of May 1994 was more serious in character to that of 1989. It went beyond simply quality control and metal testing. The critical nature of quality assurance was brought into sharp focus. Prior to this, knowledge of international quality assurance requirements was limited to large firms in Sialkot. While three-quarters of the large firms surveyed in 1993-94 were aware of the ISO 9000 standards, only $31 \%$ of SMEs sampled had heard of it. At the time, neither the local technology center, the MIDC, nor the cluster's trade body, SIMA, had disseminated information or provided technical training on the subject.

The continued competitiveness of the cluster depended on its ability to respond rapidly to the demands posed by the quality assurance pressures. Incorporating the changes necessary to conform to the new requirements, however, was not easy. In an industry reliant on traditional knowledge and metalworking expertise, the adoption of new "hard" technologies was relatively simple in that the logic of new equipment could be easily understood, often aided by reverse engineering. Local producers dismantled new machinery to learn how it functioned and then rebuilt it. As a result, a number of formerly imported technologies were made locally. Absorbing the "soft technologies" associated with quality-driven production organization was potentially more difficult. An attitudinal shift was required, wherein local producers recognized that traditional practices could be improved upon and were aware of the urgency to do so. For the Sialkot cluster, where many of these changes were perceived as going against the grain of locally embedded practices, such reorganization was unlikely to be smooth.

In the months following the FDA "ban" sales to the United States were suspended, most firms reduced production levels, some smaller units closed down while others entered new product lines (such as, for example, barber's scissors or beautician's equipment) or sought new markets in Europe, Asia and Southern Africa. A number of manufacturers tried to find alternative channels into the US market in order to circumvent the FDA's barriers. Among the hardest hit segments of the cluster were process-specialized subcontractors and suppliers of locally manufactured scrap steel (the main raw material used for disposable instruments produced for the US market).

The awareness of the necessity to upgrade was rapid even if the process of upgrading itself was gradual. Discussions on the means to acquire the requisite know-how for upgrading local practices began almost immediately, especially within the forum of the trade association (investigated in depth below). By December 1994, one large firm in Sialkot had managed to become GMP certified by the FDA. It did so by hiring the services of a foreign consultant. In April 1995, 11 months after the FDA's action, SIMA, with financial aid from the government, negotiated a contract with a US quality assurance consultancy to provide technical training for local producers to upgrade to GMP standards.

By January 1997, as a result of the training provided by the consultant, 75 producers had been certified by the FDA as conforming to current GMP standards, and were thus able to export to the United States. ${ }^{6}$ Ten months later this figure had risen to 133 firms, with a further 153 producers either undergoing training on quality assurance techniques or awaiting certification by the FDA. Moreover, two local firms had become ISO 9002 certified while at least 10 other producers were confidently expecting to be certified in the course of the next year. 
Export sales from the cluster stood at approximately US\$125 million in 1995-96, compared with US\$109 million in 1993-94. ${ }^{7}$ The numbers of exporting firms in the cluster had increased (to close to 400), as had physical production levels, while quality levels were generally acknowledged as having improved. Although the cluster has not yet fully extricated itself from the crisis there is evidence to suggest that it has managed to upgrade. In this sense, the FDA crisis may well have been a defining moment and a turning point for the cluster.

The question remains how has it done so? Moreover, what implications arise for individual firms, and for the ways in which they are organized? How have ties with local suppliers and subcontractors, and forward ties with external buyers, changed? Has horizontal cooperation that local firms have with each other, and through their trade association, become more pronounced? These questions are addressed below in Section 4 and Section 5.

\section{CHANGING HORIZONTAL TIES}

A key aspect of the response by the Sialkot surgical instrument cluster to the FDA has been the role played by the trade association, SIMA. In particular, the trade body mobilized the state to adopt a more supportive and interventionist program for the cluster. This section reviews how horizontal joint action generated cluster-wide gains.

Evidence of greater horizontal cooperation in the cluster began to emerge soon after the FDA's action in May 1994. As mentioned earlier, local producers quickly began to discuss how to face the challenge posed by quality assurance standards. Exchange of information was the one arena where the majority of firms sampled reported an increase in cooperation with other producers. Much of this discussion took place within the trade association. As a result, SIMA began formulating a collective response within a month of the import "ban" being imposed. It put together a delegation, composed predominantly of owners of large firms, to visit the United States and negotiate directly with the FDA. On failing to convince the United States regulators to accede to a phased process of GMP certification, SIMA turned to the Pakistani government for financial support to hire foreign consultants to help local producers upgrade quality management procedures. The federal government also agreed to finance, at a cost of US 1.6 million, the development of a new, internationally recognized, metal testing laboratory and a technical training facility in Sialkot, both to be managed in partnership with SIMA. ${ }^{8}$ Finally, SIMA acquired approval from the government for a revolving credit line, of approximately US\$2.5 million, to provide soft term loans to local manufacturers.

The growing importance of SIMA can be gauged from the survey data that show that of the 60 firms sampled $61.6 \%$ reported using the services of the association more now than they did before the crisis. This pattern was similar across different size categories of firms. Although the overall package took time to take shape, SIMA's response was seen by many local enterprises as the best way to address the crisis. SMEs considered the predominance of representatives of large enterprises in SIMA's delegation an advantage to the cluster. As one entrepreneur who ran a medium-sized firm explained:

Owners of large firms have better contacts, they have clout. Ministers in Islamabad will listen to them; they wouldn't give small firm owners like me even an appointment. Also, large firms have good contacts abroad, they can speak better English, they can negotiate far better on our behalf than we could (P. Ahmed, July 14, 1994).

The relatively proactive stance adopted by the association contrasts sharply with how it was perceived prior to the crisis. While SIMA has a long history, having been set up almost five decades ago, and all manufacturing and exporting firms in the cluster are members, it has traditionally been seen as relatively ineffectual. It is meant to provide information on markets, trade policy, technology and other relevant issues to its members. It is supposed to assist them in resolving technical difficulties and in dealing with the state and other regulatory bodies. It is also mandated to regulate business practices within the cluster. The 1993-94 survey found, however, a widespread consensus in the cluster that the Association was ill-informed with regards to technical and marketing information, was unable to provide technical guidance to its members and was not always effective as a 'leader' or 'voice' of the cluster's collective interests. Its most common activity was its occasional efforts at lobbying government and representing the interests of member firms with local state agencies, especially the customs and tax departments. 
What made SIMA a more vocal and effective champion of cluster-wide interests following the quality assurance crisis? In part, the explanation lies in changes that have taken place within SIMA since 1994. In 1994 there was a widespread view, especially among SMEs, that large firms dominated SIMA's management and that their interests determined the association's activities. While this perceived bias is difficult to substantiate, the majority of the annually elected chairmen of SIMA over the previous decade and a half had been owners of large firms. The Chairman has an important function within SIMA, providing executive day-to-day management and closely influencing the level of activity displayed by the association at any given time.

The continuing dominance of larger producers in the working of the trade body was brought into question by the FDA action. Representatives of large firms organized SIMA's initial reaction, the formation of the delegation. It was in their immediate interest to negotiate with the FDA and thus ease the shipment of ongoing consignments. SMEs also stood to benefit from this initiative; nevertheless large firms had the most at stake in terms of proportion of exports from Sialkot. SIMA's subsequent effort in getting state support for a consultant to provide GMP training to 200 firms within the cluster, however, provided a benefit that was particularly critical to SMEs. Large firms could have obtained GMP certification by acquiring know-how and training from consultants directly although at a price (as some did). Alternatively, they could turn to their foreign buyers for assistance on upgrading (one leading US buyer had begun to provide such aid to the large manufacturers it dealt with in Sialkot in 1994). In contrast, small firms were in a weaker position. They were less likely to have either the connections, or the large sales volume, with more quality-conscious foreign buyers to obtain the latter's support. Moreover, they lacked the resources to seek individual solutions of hiring foreign consultants to acquire the required know-how to upgrade. The cluster-wide consultancy service, financed by the state and organized through SIMA, made such know-how more widely accessible, thus making it possible for many of the smaller producers to obtain GMP certification and continue competing with their larger local rivals.

How did this happen? In effect, there appears to have been a discernible shift in power within
SIMA since 1994. At the time of the crisis, the association was led by a chairman whose interests were said to be closely tied to those of the leading large firms in the cluster. In 1995, only five firms (all large units) had managed to get through the GMP hurdles set by the FDA. Moreover, it had taken the association a full year to get an agreement with a foreign consultant to obtain quality management training for the cluster. In the annual elections held in 1995, the frustration felt by the SMEs in the cluster at the slow pace of progress came to a head. The sense of being marginalized within SIMA led to a process of mobilization by SMEs. Some of the more dynamic SMEs built a loose coalition with a few of the leading large firms in the cluster and a new panel of office bearers was voted in the 1995 elections for SIMA's executive committee. This panel, which was re-elected in 1996, has as its Chairman an owner of a large enterprise. He is respected widely within the cluster and much credited for his efforts in accelerating the introduction of consultancy services on a cluster-wide basis. Thus, as one SME owner reports

SIMA is now more active as a consequence of the GMP and FDA issue. Before the big firms would hinder the activity of SIMA and of smaller firms. Now, through SIMA, all firms in the cluster, big and small, can get the help they need to get through this [quality assurance] problem (Rashid, January 21, 1997).

While individual agency mattered, the broad coalition of interests and the mobilization of collective concerns of SMEs made such progress feasible.

Of the steps initiated by SIMA, the most important was clearly seeking external technical knowledge on quality management. Acquiring the know-how, via international consultants, to adopt the record keeping and documentation procedures necessary for quality assurance certification became the critical element in becoming GMP certified.

As mentioned earlier, implementing quality management procedures, including reorganizing production to conform to quality assurance requirements at each stage of production is in many ways more difficult than the acquisition of hard technologies. It requires quality training, new management practices and the inculcation of quality-driven values. A number of external service providers, both Pakistani and foreign, began offering training and consultancy services to local producers soon after the May 1994 FDA action. The first firm to be 
GMP certified obtained its certificate by hiring, at a substantial cost, such a consultant. The response of this large firm was a clear sign of individual action in response to the FDA crisis. It bought the technical services and know-how it needed to get it through the FDA barrier. Its costs were recuperated through its ability to sell again in the US market.

While this firm pointed the way out of the crisis, SIMA's action, in bringing in a quality consultant for the cluster as a whole, transformed the situation making such soft technologies available to most firms in the cluster. The mandate for the consultant was to provide training to 200 local producers on the management, documentation, and record keeping practices required for GMP certification. By late 1997, the US consultant firm had been operating in Sialkot for over a year, using the premises of the trade association as its base. Among the 133 firms that it helped through the FDA's certification process were small, medium and large enterprises. Most, although not all, large firms became GMP certified. Among smaller enterprises, the fact that the consultancy services were heavily subsidized meant that they were able to acquire the technical expertise that would otherwise have been beyond their reach. As the consultant's representative observed "our project in Sialkot is operating on a level playing field - we provide services to everyone irrespective of their size" (D. Narejo, January 28, 1994).

Horizontal joint action, especially through the cluster's trade body, has played an important part in making it possible for many local firms to cross the GMP certification barrier. What does this certification process, and the quality assurance problem in general, imply for vertical ties that Sialkot's manufacturers have with their suppliers, subcontractors and buyers? Is there greater cooperation in these relationships as a consequence of the quality assurance crisis?

\section{CHANGING VERTICAL TIES}

The hypothesis put forward in this paper is that the upgrading required to conform to quality assurance standards necessitates greater inter-firm cooperation, both in horizontal and vertical linkages. The latter is particularly important. Quality assurance, to be effective, has to be ensured at all levels of the supply chain. This requires upgrading of suppliers, implying a need for greater, quality-intensive, information flows within the supply chain, potentially closer monitoring and effectively a greater degree of reliance that suppliers meet new standards. In the new competitive scenario, failure by suppliers to conform to quality assurance standards is potentially more harmful to local producers. By the same token, once suppliers are themselves certified as meeting quality assurance standards, the transaction costs in vertical ties would decline, providing an incentive to move to "arms-length" contracts (Foss, 1996). This section draws on sample and case study evidence to examine if producers in the Sialkot cluster increased vertical cooperation with their local suppliers and subcontractors and their external buyers. In doing so, it also explores how vertical ties are changing as a consequence of the quality assurance crisis.

One of the main findings of the earlier study on Sialkot (Nadvi, 1996) was the importance of vertical linkages. Almost all of the 57 firms surveyed in 1993-94 used subcontractors for particular process activities, and relied on local suppliers for stainless steel and other inputs, raw material and machinery. Similarly, most firms dealt directly with foreign buyers. Ties with local subcontractors and foreign buyers were often close. The majority of producers reported assisting subcontractors in production organization (cited by $56 \%$ of firms surveyed in 1993-94), and engaging in technical discussions on issues relating to product quality. Similarly, manufacturers often sought and obtained help from their buyers. Buyers were one of the more frequently cited sources (reported by $85 \%$ of sampled respondents) for technical and marketing information, and according to $46 \%$ of the sample had assisted them in raising quality standards. Such ties were especially close for firms engaged in subcontracting, or in joint venture partnerships, with foreign producers.

The FDA crisis of 1994 could result in two distinct ways of reorganizing ties with subcontractors. The first response was of producers internalizing quality-critical stages in production, where transaction costs of monitoring and ensuring that quality assurance requirements had been met outweighed the benefits of subcontracting. The second response was of firms continuing, possibly even extending, the practice of subcontracting and engaging in greater cooperation in vertical linkages as the preferred path for upgrading. 
There was some evidence for both types of responses. Most large firms had already internalized a number of the more quality-critical stages in production. There were also signs that, in response to the FDA crisis, large firms planned to further internalize production. This was most clearly seen in the case of firms entering into joint venture partnerships. For example, one large firm, that had signed a joint venture agreement with a German partner, stated that the planned joint venture unit would be a fully integrated plant with no subcontracting-out. Another large firm proposed to bring key subcontractors into its newly constructed facility to ensure that they worked exclusively for the firm and were regularly supervised and monitored.

The second response, of closer collaboration in ties with subcontractors, however was more common. This is not entirely surprising because quality concerns were already a key element of vertical ties prior to the FDA's action. Maintaining quality standards and ensuring that product specifications were met was the central aspect of interaction between manufacturers and subcontractors. Assistance and even supervision was regularly provided to subcontractors to ensure quality levels especially where problems occurred (reported by $58 \%$ of firms sampled in 1993-94). The new quality assurance standards, however, require more systematic and formalized inspection and documentation. The remainder of this section analyzes how vertical ties changed in response to the new quality assurance principles imposed by the FDA.

\section{(a) Backward ties}

Take first the ties with local input and raw material suppliers. No respondent reported a decline in the degree of cooperation in ties with suppliers following the FDA crisis. While many aspects of these relationships, such as negotiations over payment and delivery, remain as before, in other areas there has been some increase in cooperation. As Table 1 indicates, over half the sample had increased the exchange of information and experience with their suppliers. This was especially so on issues of quality. Thirty percent of firms sampled stated that cooperation with suppliers over quality improvement had risen since the 1994 crisis. There was no significant pattern across firm size.

A key aspect of the quality assurance crisis relates to the quality of stainless steel. It is widely reported in the cluster that pressure from local producers and from the trade association has resulted in improvements in the standards and manufacturing processes employed by the scrap-based steel re-rolling sector in nearby Gujranwala. Local respondents now consider local scrap-based stainless steel to be on par, in quality terms, with some imported stainless steel. Due to the FDA's pressure, and in line with the GMP requirements, all steel bought locally is metal tested before it is forged, and has the required traceability records. This ensures for manufacturers (and their buyers) that, unlike before, the metal composition of the steel conforms to requirements, that these quality standards are uniform across the whole sheet of metal, and that the steel producer can be held accountable. The improvement in local stainless steel has brought with it an increase in steel prices (by up to $50 \%$ ), much of which has been absorbed by producers thanks to the devaluation of the Rupee over this period. The key point to note is that, in some respects cooperation with suppliers has increased and generated cluster-wide benefits.

Table 1. Improvements in cooperation with suppliers ${ }^{\text {a }}$

\begin{tabular}{lccccc}
\hline & $\begin{array}{c}\text { All firms } \\
N=60(\%)\end{array}$ & $\begin{array}{c}\text { Small firms } \\
N=21(\%)\end{array}$ & $\begin{array}{c}\text { Medium firms } \\
N=22(\%)\end{array}$ & $\begin{array}{c}\text { Large firms } \\
N=17(\%)\end{array}$ & $\begin{array}{c}\text { Kendall } \tau \\
\text { value }\end{array}$ \\
\hline $\begin{array}{l}\text { Increase in exchange of information } \\
\text { and experiences }\end{array}$ & 55.0 & 61.9 & 50.0 & 53.0 & -0.028 \\
$\begin{array}{l}\text { Increase in cooperation to improve } \\
\text { quality }\end{array}$ & 30.0 & 23.8 & 31.8 & 35.3 & 0.089 \\
$\begin{array}{l}\text { Change suppliers less often than } \\
\text { before FDA crisis }\end{array}$ & 16.7 & 23.8 & 0 & 23.5 & -0.064 \\
\hline
\end{tabular}

a Source: Author Survey (1997). 
Turning to ties with subcontractors, the picture is more complex. A core requirement of international quality assurance systems is the documentation of each lot and batch of production at each and every stage in production. This implies that all batches have to carry record cards for each process, listing who undertook the task, the defects that occurred at that stage, the amount that was rejected as a consequence, and the results of each stage-wise quality inspection. Where processes are put-out by manufacturers to subcontractors, the latter are required to complete these documents, referred to locally as "travel cards," for each batch and each stage of the process that they undertake. The firm is responsible for the subcontractor fulfilling these requirements. In this situation the cost to the firm of the subcontractor failing to keep to the quality assurance stipulations are high.

With one exception, manufacturers reported that subcontractors had difficulty in furnishing the correct documentation. Unlike most manufacturers subcontractors are often illiterate, rarely maintain appropriate records, and usually lack the management training to meet quality assurance assessment and documentation needs. Consequently, some firms "fill-in" their subcontractor's record cards themselves, a practice which raises doubts on the legitimacy of overall standards certification within the cluster. Others carry out regular inspections and monitoring of subcontractors for each batch lot. A few firms, recognizing the higher transactions costs of monitoring, have begun to lower their extent of subcontracting. Others have brought some of their key subcontractors into their premises in order to ensure monitoring and appropriate stage-wise documentation.

The extent to which subcontracting declined as a consequence of the FDA crisis is reflected in Table 2 below. As this shows, while the internalization of most key processes has increased, this has not, with the exception of the filing stage, taken place on a large scale. The variation in this pattern by firm size is also not significant. At the same time, it has to be noted that subcontracting did not appear to increase in the cluster. Only three out of the 60 firms surveyed reported increasing subcontracting in any given process.

The aggregated data would imply that the increased transactions costs associated with quality assurance monitoring and documentation in any given process, with the possible exception of the filing process, do not substantively outweigh the gains that firms accrue from subcontracting. This, however, veils important differences within the cluster. Case study evidence suggests that the process of internalization was significant for some large firms.

Take the example of Amir Surgicals, a large firm which in 1994 had 125 employees and sales in excess of US\$1 million, the bulk of which $(90 \%)$ was to the US market. Prior to the FDA action, the firm subcontracted all of its filing tasks to some 30 subcontractors as well as half of its polishing work to another 25 subcontractors. It has now internalized some of these activities and foresees reducing its reliance on external subcontractors even further. Since 1994 sales have increased and the firm is expanding. As part of its expansion plan, a new unit is being built on Sialkot's outskirts. In this facility the firm plans to internalize all processes. It will continue to use some of its current subcontractors, especially for labor-intensive filing tasks. They will, however, have to work from within the new premises.

It costs us a lot of time and effort to monitor that the subcontractors follow the correct quality assurance

Table 2. Decline in extent of subcontracting in key process activities ${ }^{\text {a }}$

\begin{tabular}{lccccc}
\hline $\begin{array}{l}\text { Reduction in extent of subcontracting } \\
\text { since FDA crisis }\end{array}$ & $\begin{array}{c}\text { All firms } \\
N=60(\%)\end{array}$ & $\begin{array}{c}\text { Small firms } \\
N=21(\%)\end{array}$ & $\begin{array}{c}\text { Medium firms } \\
N=22(\%)\end{array}$ & $\begin{array}{c}\text { Large firms } \\
N=17(\%)\end{array}$ & $\begin{array}{c}\text { Kendall } \tau \\
\text { value }\end{array}$ \\
\hline Key processes & & & & & \\
Forging & 8.3 & 4.8 & 9.1 & 11.8 & 0.082 \\
Milling \& Grinding & 11.7 & 4.8 & 13.6 & 17.7 & 0.055 \\
Filing & 23.3 & 14.3 & 27.3 & 29.4 & 0.139 \\
Polishing & 10.0 & 14.3 & 4.5 & 5.9 & -0.040 \\
Heat Treatment & 3.4 & 4.8 & 0 & 5.9 & -0.081 \\
\hline
\end{tabular}

\footnotetext{
a Source: Author Survey (1997).
} 
procedures. By having these subcontractors located within our larger compound we will be able to ensure that they prioritize our work and that they are following the correct quality procedures. Also it becomes easier for us to do the documentation which will come with the ISO 9000 (S. Amir, January 21, 1997).

Amir Surgicals gains in that its quality-related monitoring costs are lowered while the labor flexibility that comes with subcontracting is retained.

In 1994 the extent of subcontracting was already inversely related to firm size. As Figure 1 makes clear, most medium and all large firms internalize some intermediate processes (such as polishing) and all finishing tasks. The pattern of production emerging in some large firms, as illustrated in the case of Amir Surgicals above, indicates a desire to retain aspects of subcontracting while minimizing monitoring costs by "bringing subcontractors into the firm." Supervision and monitoring costs associated with quality assurance are kept low and core subcontractors are available on an assured basis. For subcontractors, this practice is considered advantageous in that they obtain rent-free space, their search costs for new work are much reduced as they can expect a regular stream of work, and they get access to new forms of knowledge (and potentially training) from outside the cluster. Subcontractors remain responsible for their own labor, its training and for some machinery, and they continue to be paid on a piece-rated job basis. Firms that have adopted this practice have identified a core group of first-tier subcontractors with whom ties are closer. Subcontractors left outside this first-tier are in a more precarious position, with poorer access to external knowledge and to a guaranteed flow of work.

This trend also has consequences for small and medium-sized firms. Take the case of Unimed, a medium-sized firm with a workforce of 31 persons (six of whom were family members) in 1994, and sales of US\$350,000 primarily to the German market. What distinguished Unimed from other SMEs was its adherence to high quality standards and the fact that it had acquired the technology to manufacture higher value-added instruments. It relied extensively on process specialized subcontractors with whom it had particularly close ties. A number of its subcontractors reported in 1994 that they had gained more in technical feedback through their relationship with Unimed than with many large firms. With rising quality standards in the cluster, and increasing numbers of GMP certified SMEs, Unimed lost its quality-based competitive edge. Unable to retain key buyers, it has seen a drop in sales. As a result, the volume of work subcontracted out has also declined. Many of Unimed's more dynamic subcontracting units are now seeking closer ties with large firms which are more likely to provide them with a continued flow, and potentially larger volume, of work. Consequently, the intensity and depth of the technical dialogue that the Unimed formerly enjoyed with its subcontractors has diminished.

Despite the somewhat uneven patterns of change in subcontracting, it appears that cooperation with subcontractors has increased following the quality assurance pressures. As Table 3 shows, three-quarters of sampled firms reported an increase in cooperation with sub-

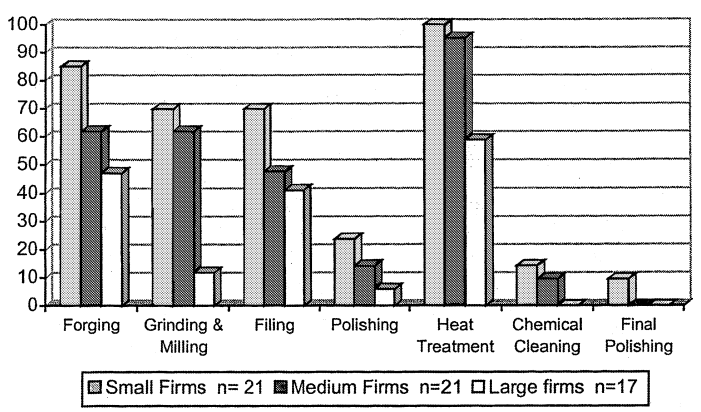

Figure 1. Subcontracting in key process activities by firm size. (Kendall $\tau$ significant at 95\% for grinding and filing processes and at $90 \%$ for forging.) 
Table 3. Improvements in cooperation with subcontractors ${ }^{\text {a }}$

\begin{tabular}{lccccc}
\hline & $\begin{array}{c}\text { All firms } \\
N=57(\%)\end{array}$ & $\begin{array}{c}\text { Small firms } \\
N=21(\%)\end{array}$ & $\begin{array}{c}\text { Medium firms } \\
N=21(\%)\end{array}$ & $\begin{array}{c}\text { Large firms } \\
N=15(\%)\end{array}$ & $\begin{array}{c}\text { Kendall } \tau \\
\text { value }\end{array}$ \\
\hline $\begin{array}{l}\text { Increase in exchange of information } \\
\text { \& experiences }\end{array}$ & 64.9 & 57.1 & 66.7 & 73.3 & 0.140 \\
$\begin{array}{l}\text { Increase in cooperation to improve } \\
\text { quality }\end{array}$ & 75.5 & 71.4 & 80.9 & 73.3 & 0.172 \\
$\begin{array}{l}\text { Increase in cooperation in technical } \\
\text { upgrading }\end{array}$ & 12.3 & 4.8 & 9.5 & 26.7 & $0.238^{*}$ \\
$\begin{array}{l}\text { Increase in cooperation in production } \\
\text { organization }\end{array}$ & 35.1 & 23.8 & 42.9 & 40.0 & 0.180 \\
$\begin{array}{l}\text { Increase in cooperation in labor } \\
\text { training }\end{array}$ & 22.8 & 14.3 & 23.8 & 33.3 & 0.186 \\
$\begin{array}{l}\text { Change subcontractors less often } \\
\text { than before FDA crisis }\end{array}$ & 36.9 & 23.8 & 47.6 & 40.0 & 0.164 \\
\hline
\end{tabular}

Kendall $\tau$ significant at $90 \%$.

a Source: Author Survey (1997).

contractors on quality improvement. Almost two-thirds of the sample stated that there was a greater exchange of information and experience in these ties. Moreover, a third of the total sample noted that subcontractors were changed less frequently than before, indicating more consistent arrangements. In none of these areas of increased cooperation was firm size significant.

No firm reported a decline in cooperation with subcontractors as a consequence of the quality assurance pressures. Yet, there are clear gaps where increased cooperation did not occur. Thus, $88 \%$ of respondents report no increase in cooperation with subcontractors on the issue of technical upgrading of equipment. Some $77 \%$ report no change in cooperation on labor training (where the onus continues to rest with the subcontractor), while $65 \%$ state no change in cooperation with subcontractors on improving production organization. Cooperation with suppliers, and more so with subcontractors, has focused on information exchange and on discussions aimed at raising quality standards. While not denying the importance of such exchanges, further collaboration in supply chains on issues of labor training, production organization and technical upgrading, have yet to take place.

These findings suggest that the demands of quality assurance are changing the pattern of subcontracting in the cluster, with greater differentiation between producers and among subcontractors. At the same time, cooperation with subcontractors has tended to increase.

\section{(b) Forward ties}

Forward linkages with external buyers were seen in 1994 as a key source for the soft technology necessary to pass the new quality assurance standards, and thus a critical link for local producers to upgrade. As the manager of one firm suggested: "With these new requirements on quality control, we need to have ties with foreign buyers to get us through the new standards" (S. Tariq, July 16, 1994). In 1994, some buyers had begun to take the initiative, assisting local firms by providing quality assurance training manuals and developing management processes and software packages for quality assurance documentation.

Since then, ties with buyers have altered in several ways. Although the overall quality standards of Sialkot's instruments has improved, and a number of local producers are now GMP certified, unit prices of instruments manufactured in Sialkot have fallen in the world market. According to local respondents, this decline in price is a direct outcome of the competition prevalent in the US market, particularly among US-based Pakistani market agents. More established and larger US buyers have gained. The fact that a significant number of Sialkot's producers, both large and small firms, are now GMP certified has also had an impact. Thus, while there is evidence that the crisis led to the forging of closer relationships between some buyers and producers, many buyers moved to more transient, market-oriented ties in order to benefit from the overall 
drop in price and the rising quality standards prevalent in the cluster.

This, for example, was the most important factor behind the decline in the fortune of Unimed, the medium-sized firm discussed above. Despite the fact that it did not sell to the US market, Unimed was one of the earliest SMEs to seek GMP certification. According to the owner, "the GMP certification was free, so we thought it was worthwhile going through it, and we hoped it might impress some of our European parties [buyers] as well" (Rashid, January 22, 1997). Yet, it has had to compete with a larger number of local producers trying to sell in the relatively more quality-driven European market, following the initial FDA ban. Unimed lost orders with some of its longstanding buyers who could now source more cheaply from other quality assured suppliers in the cluster.

While the decline in prices was a general experience, the relationships with buyers did not always deteriorate. In fact, Table 4 shows increases in cooperation with buyers following the quality assurance crisis: $62 \%$ of firms sampled reported an increase in exchange of information, while $65 \%$ reported greater cooperation with buyers over quality control and quality improvement issues. In contrast, only a minority of firms experienced increased cooperation with buyers in developing quality assurance systems and reorganizing production. Finally, a quarter of the sample (and almost half the large firms interviewed) stated that buyers were changed less often than before the FDA crisis, indicating that these ties had become more consistent and long standing. Unlike backward linkages, firm size appeared to be more significant a factor in upgrading of forward ties. Large firms tended to have increased cooperation with buyers more so than small and medium enterprises.

Case study evidence again helps bring out more sharply how the nature of forward ties are changing. Take again the example of Amir Surgicals. Unlike Unimed, which saw its close links with its European buyers weaken, Amir Surgicals has become more closely tied to its leading buyer. In 1994, the firm owner had stated his preference for a diversified set of buyers within and across his leading export markets. At that time he pointed out that

we have one very big buyer in the US who takes about $60 \%$ of our total output. He would like to purchase more from us. In fact to satisfy his demand we would have to more than double our capacity. But we don't want to get too tied and dependent on him, although this American client has been very good for our business. Instead we try to ensure that at least $40 \%$ of our production is sold to other buyers, not only in the US, but also in Europe and the Far East. It is good to be diversified this way (S. Amir, Febuary 22, 1994).

This diversification proved difficult to maintain. Following the FDA's action, Amir Surgical was faced with the prospect of having to shut down its operation given that the bulk of its production was destined for the US market. The firm sought alternative end markets, in Europe and especially in Japan. To some extent this was achieved, nevertheless the dependence

Table 4. Improvements in cooperation with buyers ${ }^{\text {a }}$

\begin{tabular}{lccccc}
\hline Ties with buyers & $\begin{array}{c}\text { All firms } \\
N=60(\%)\end{array}$ & $\begin{array}{c}\text { Small firms } \\
N=21(\%)\end{array}$ & $\begin{array}{c}\text { Medium firms } \\
N=22(\%)\end{array}$ & $\begin{array}{c}\text { Large firms } \\
N=17(\%)\end{array}$ & $\begin{array}{c}\text { Kendall } \tau \\
\text { value }\end{array}$ \\
\hline $\begin{array}{l}\text { Increase in exchange of information } \\
\text { \& experiences }\end{array}$ & 61.7 & 47.6 & 63.6 & 76.5 & $0.214^{*}$ \\
$\begin{array}{l}\text { Increase in cooperation to improve } \\
\text { quality }\end{array}$ & 65.0 & 61.9 & 81.8 & 47.1 & -0.050 \\
$\begin{array}{l}\text { Increase in cooperation in technical } \\
\text { upgrading }\end{array}$ & 16.6 & 4.8 & 18.2 & 29.4 & $0.251^{* *}$ \\
$\begin{array}{l}\text { Increase in cooperation in produc- } \\
\text { tion organization }\end{array}$ & 3.4 & 0 & 9.1 & $31.3(n=15)$ & 0.021 \\
$\begin{array}{l}\text { Increase in cooperation in develop- } \\
\text { ing quality assurance system } \\
\text { Change buyers less often than }\end{array}$ & $29.3(n=57)$ & $30.0(n=20)$ & 27.2 & 47.0 & 0.021 \\
\begin{tabular}{l} 
before FDA crisis \\
\hline
\end{tabular} & 26.7 & 9.5 & 27.3 & & $0.370 * *$ \\
\hline
\end{tabular}

\footnotetext{
* Kendall $\tau$ significant at $90 \%$.

** Kendall $\tau$ significant at $95 \%$.

a Source: Author Survey (1997).
} 
on the US market remained. Its leading US buyer offered to assist, by selling Amir's output under its own brand name and providing its own quality guarantees.

They [the US buyer] were willing to put their quality reputation on the line for us. This enables us to get around the FDA barriers and to continue production at a time when most of the industry in Sialkot were barred from the US market (S. Amir, January 21, 1997).

There was however a cost to this arrangement. The buyer placed a condition that Amir Surgical would not market its product in the United States through any other agent. This buyer now takes three-quarters of the firm's output. In addition to this dependence, further disadvantages are emerging from this agreement.

My US buyer sells a smaller and more standardized range of instruments than I used to manufacture before. So there are a number of items that were very profitable which I am no longer producing. In terms of prices I am also tied (S. Amir, January 21, 1997).

The firm's predicament is not unique. A number of local producers report a growing reliance on key foreign buyers since the FDA crisis. Buyers have also begun to adjust their relationships with Sialkot's manufacturers and in doing so have tried to improve their position vis-à-vis the cluster. There are two ways in which this has happened. The first is, the experience observed in Amir Surgicals, where the weak position of the producer has allowed the buyer to negotiate better terms. The relationship between specific buyers and producers is sustained, but the terms of trade are shifting in the former's favor. Second, buyers have begun to shop around much more than before. Thus, as with Unimed, long-standing buyers have sought out cheaper alternative sources in Sialkot.

In fact, as a consequence of the fact that a significant number of local producers have become GMP certified and that prices have fallen, technical ties that buyers had with Sialkoti producers have in some cases weakened. Take, for example, the case of a leading US buyer of disposable instruments-Ameritrade. Prior to the FDA crisis of 1994 Ameritrade directly monitored the production quality of its dozen large suppliers in Sialkot. Frequent and regular on-site inspections were carried out and, where needed, technical assistance was provided directly at the shop floor to resolve quality related problems. In this process, Ameritrade's Sialkot representative became a technical knowledge bank for its local suppliers. Many local producers considered this a key relationship and Ameritrade itself also benefited: reject rates declined substantially.

In keeping with the importance that Ameritrade attached to its technical assistance role within the cluster, Ameritrade's Sialkot office began to assist its local suppliers soon after the FDA crisis. It helped them develop statistical process control packages and design documentation for quality assurance systems. At the same time, Ameritrade's representative was clear that Sialkot's producers had to adopt rapidly the quality assurance requirements or lose key buyers. Since 1994 the nature of Ameritrade's relationship with the cluster has radically changed. It continues to purchase large quantities of Sialkot-made surgical instruments, almost at the same level as in 1994, but it no longer maintains close technical ties with its local suppliers and has downsized its Sialkot operation. The local representative in Sialkot provides Ameritrade with intelligence on the cluster as a whole, on local firms from whom purchases are being made and on the progress these firms have made on quality assurance. Given that all instruments now being sold in the US are GMP certified, however, the quality-related transaction costs that Ameritrade previously had to bear are now much reduced. Moreover, this reduction in quality-related transaction costs has been achieved without Ameritrade's intervention.

Ameritrade, and other buyers like it, realized that once the Pakistani government got interested into the quality assurance issue and were keen to provide assistance to the cluster, the FDA problem could be solved without them [the buyer] having to invest further in raising quality standards. That is why we have almost stopped our earlier quality control programme here (N. Rahim, January 21, 1997).

In summary, both the quantitative and the qualitative data help bring out the ways in which vertical ties are changing in the Sialkot cluster. Although at times apparently contradictory, case study and survey findings together provide a more nuanced understanding of how vertical ties have evolved as a consequence of pressures to meet international quality assurance standards. Ties with local steel suppliers 
have improved, resulting in a higher quality raw material base. As far as ties with subcontractors are concerned, the higher costs of monitoring quality have led to some large firms internalizing more activities and "bringing subcontractors into the premises." The survey evidence suggests however that internalization is not a universal trend, not even among large firms. SMEs, in particular, continue to rely on subcontractors for a wide range of tasks. Nevertheless, subcontractors are also becoming more differentiated as large firms seek to develop first-tier suppliers. This has consequences for SMEs who formerly had close, and often technically rich, ties with their subcontractors. Forward ties to foreign buyers have also become weaker in some cases, and in others closer and often more dependent. Buyers have been able to bring about a shift in their favor in the terms of trade as price competition has forced down unit prices for Sialkot's instruments. Is this a long-term response on the part of buyers, or are they likely to (re)build technical ties with Sialkot's producers as prices stabilize? Again the evidence from the quantitative survey suggests that greater cooperation in vertical ties is most pronounced in links with buyers, especially for larger firms. But such increases in cooperation were limited to exchange of information and quality improvement and did not extend to broader concerns of technological and organizational change.

\section{COOPERATION AND PERFORMANCE: IS THERE A RELATIONSHIP?}

This section statistically evaluates the relationship between firm performance and cooperation, both vertical and horizontal. To recap, our contention has been that Sialkot's firms must engage in greater joint action to face the challenges posed by the new quality assurance standards. Section 4 and Section 5 indicate that, while uneven, increasing collaboration has been observed in both horizontal and vertical linkages. This section examines whether firms that have increased cooperation have performed better. Evaluating the relationship between changes in levels of cooperation and firm growth allows for an assessment of the cluster's growth trajectory. In addition, disaggregating this relationship facilitates an appraisal of the types of interfirm relationships, both local and external, that are becoming more critical for growth. The discussion below is structured as follows. First, using the survey data, indices of performance and cooperation are generated, and the correlation between these various indices analyzed. Second, regression analysis is carried out to assess if there is a significant association between cooperation and performance.

Cooperation indices were developed for ties with suppliers (COPSUPL2), with subcontractors (COPSUBC2), with buyers (COPBUYR2), with other firms (COPFIRM2) and with the trade association (COPSIMA2). ${ }^{9}$ Table 5 provides the frequency distribution for these indices of cooperation.

The majority of firms sampled stated there had been a small increase in cooperation in all the cooperation indices. The index for cooperation with other firms was dropped from subsequent analysis as none of the sampled firms reported an index value of greater than 0.5. The extent of such horizontal collaboration was limited and had not changed since the FDA crisis. The only area where there was a significant increase in such horizontal cooperation was in exchange of information and experience with other firms $(55 \%$ of the sample reporting an increase), much of which took place at the time of the crisis and had since diminished.

Table 5. Changes in cooperation indices since the FDA crisis

\begin{tabular}{|c|c|c|c|c|c|c|}
\hline & $\begin{array}{c}\text { Big increase } \\
>1.0 \\
(\%)\end{array}$ & $\begin{array}{c}\text { Small increase } \\
0-1.0 \\
(\%)\end{array}$ & $\begin{array}{c}\text { No change } \\
0 \\
(\%)\end{array}$ & $\begin{array}{c}\text { Small decrease } \\
-1.0 \text { to } 0 \\
(\%)\end{array}$ & $\begin{array}{c}\text { Big decrease } \\
>-1.0 \\
(\%)\end{array}$ & \\
\hline COPSIMA2 & 11.7 & 61.7 & 25.0 & 1.7 & 0 & $N=60$ \\
\hline COPFIRM2 & 0 & 53.3 & 46.7 & 0 & 0 & $N=60$ \\
\hline COPSUPL2 & 0.7 & 54.9 & 41.7 & 1.7 & 0 & $N=60$ \\
\hline COPSUBC2 & 11.7 & 70.0 & 18.3 & 0 & 0 & $N=60$ \\
\hline COPBUYR2 & 5.1 & 72.4 & 17.2 & 5.1 & 0 & $N=58$ \\
\hline
\end{tabular}


The aggregated performance variable (PERF2) was developed through principal component analysis, using the SPSS package. PERF2 consisted of the three performance variables that had the highest factor loadings for the main factor (which was seen to account for $39.6 \%$ of the total variation). These are: growth over the past five years in sales (Q2ASALES), improvements in product quality (Q2FQUAL), and in employment (Q2GWRKRS).

As a first step in assessing the relationship between the aggregate measure of performance (PERF2) and the cooperation indices, Kendall Correlation Coefficients were generated. As Table 6 shows, the performance measure is significantly and positively correlated (at the $1 \%$ level) with the cooperation with buyers index (COPBUYR2), and with the cooperation with subcontractors index (COPSUBC2). The coefficient is particularly high with cooperation with buyers suggesting that overall performance and firm growth is most closely associated with collaborative ties with buyers $(0.436)$, followed by ties with subcontractors (0.286). Ties with suppliers also has a positive association on performance, however, this is only significant at the 10\% level. Interestingly, collaboration through the trade association SIMA appears not to be associated with performance. This result, while appearing to diverge from what the qualitative findings suggests, supports the notion that sequencing and timing of support is important. SIMA played a critical role at the time of the crisis through a number of strategic interventions. Once the required path to address the FDA's concerns had been adopted, its influence diminished.
It is also apparent that (at the $1 \%$ level of significance) there is a positive correlation between cooperation with suppliers and cooperation with subcontractors. This suggests that firms which cooperate more closely with subcontractors do the same with input suppliers. There is no significant relationship however between cooperation in backward ties and cooperation with buyers. This is an important result, suggesting that while performance is most closely related to improved ties with buyers, greater cooperation with buyers is not correlated with improved ties with suppliers and subcontractors. Clearly, this indicates a weakness in the vertical chain relationship. Firms appear to address concerns of improving their ties with external buyers independently of their relationships with local suppliers and subcontractors.

It is important to consider whether there is a causal relationship between increasing cooperation and improved performance. To explore this, simultaneous and step-wise regression methods were used to estimate the following equation:

$$
\begin{aligned}
\text { PERF } 2= & \beta_{1}+\beta_{2} \text { COPSIMA } 2 \\
& +\beta_{3} \text { COPSUPL } 2+\beta_{4} \text { COPSUBC } 2 \\
& +\beta_{5} \text { COPBUYR } 2 .
\end{aligned}
$$

The simultaneous multiple regression led to the coefficients for the independent variables shown in Table 7.

While the $R^{2}$ value is relatively low, there is a clear positive and significant coefficient for the cooperation with buyers and cooperation with subcontractors indices. As can be expected this

Table 6. Correlation of performance and cooperation (Kendall coefficients)

\begin{tabular}{lcccc}
\hline COPSUPL2 & 0.1768 & & & \\
& $N(60)$ & & & \\
COPSUBC2 & Sig 0.090 & & & \\
& 0.2235 & 0.3739 & & \\
COPBUYR2 & $N(57)$ & $N(57)$ & & \\
& Sig 0.029 & Sig 0.000 & & \\
& 0.0846 & 0.0878 & 0.1225 & \\
PERF2 & $N(58)$ & $N(58)$ & Sig 0.238 & 0.4358 \\
& Sig 0.403 & Sig 0.406 & 0.2861 & $N(58)$ \\
& 0.0759 & 0.2011 & $N(60)$ & Sig 0.000 \\
& $N(60)$ & Sig 0.051 & Sig 0.005 & COPBUYR2 \\
\hline
\end{tabular}

\footnotetext{
${ }^{a}$ (Coefficient/(Cases)/2-tailed Significance).
} 
Table 7. Simultaneous multiple regression

\begin{tabular}{lc}
\hline CONSTANT & -0.033 \\
COPSIMA2 & -0.053 \\
COPSUPL2 & 0.291 \\
COPSUBC2 & $0.513^{*}$ \\
COPBUYR2 & $1.043^{* * *}$ \\
Multiple $R: 0.611$ & $R^{2}: 0.374$, Adjusted $R^{2}: 0.323$
\end{tabular}

* $T$-value significant at $10 \%$.

*** $T$-value significant at $1 \%$.

Table 8. Step-wise regression

\begin{tabular}{lc}
\hline CONSTANT & -0.039 \\
COPSUBC2 & $0.581^{*}$ \\
COPBUYR2 & $1.085^{* *}$ \\
Multiple $R: 0.603$ & $R^{2}: 0.364$, Adjusted $R^{2}: 0.340$ \\
\hline
\end{tabular}

* $T$-value significant at $5 \%$.

** $T$-value significant at $1 \%$.

is further borne out by the step-wise regression method (where the variables COPSIMA2 and COPSUPL2 were dropped). This results in a slightly better fit, and a higher level of significance for the variable COPSUBC2 (see Table 8).

These findings substantiate the earlier results that performance (and thus growth) over the previous five years has been associated with increasing cooperation in ties that local firms had with their buyers and their subcontractors. Cooperation in forward and backward ties influence performance. There is no evidence to suggest, however, that this is the case for horizontal cooperation, nor is it clear that cooperation in forward ties is necessarily associated with cooperation further down the supply chain.

To further strengthen this finding, it would be important to see how the performance is influenced by other factors not directly related to cooperation. This requires conducting a regression analysis for the same equation above but with a further independent variable for firm size (SIZE). This is reported below using a simultaneous equation method (see Table 9).

Introducing firm size into the picture clearly has some influence on the specifications of the equation and on the relationship with performance. Firm size is positively and significantly correlated with performance. It is also apparent however, that cooperation with buyers (COPBUYR2) remains the variable most
Table 9. Simultaneous equation regression with firm size

\begin{tabular}{lc}
\hline CONSTANT & $-0.506^{*}$ \\
COPSIMA2 & 0.076 \\
COPSUPL2 & 0.390 \\
COPSUBC2 & 0.264 \\
COPBUYR2 & $0.926^{* * *}$ \\
SIZE & $0.285^{* *}$ \\
Multiple $R: 0.654$ & $R^{2}: 0.428$, Adjusted $R^{2}: 0.370$ \\
\hline
\end{tabular}

* $T$-value significant at $10 \%$.

** $T$-value significant at $5 \%$.

*** $T$-value significant at $1 \%$.

closely associated with growth. None of the other variables are significant. Carrying out this exercise using a step-wise regression method reveals similar results. What this implies is that if firm size is taken into consideration, greater cooperation in forward ties still has a positive and significant influence on performance.

\section{CONCLUSION}

The evidence above shows that, in response to the pressures posed by the quality assurance crisis, there has been upgrading in manufacturing practices in the Sialkot surgical instrument cluster. Furthermore, such upgrading has involved greater joint action, both in vertical and horizontal ties. Joint action has also been positively associated with improved firm performance. This suggests not only that the collective efficiency model continues to be valuable in explaining the competitive advantages that local producers gain by virtue of being located in a sector specialized cluster, but also that sustained competitiveness demands local joint action.

In terms of backward ties it appears that links with suppliers have led to significant improvements in the quality of stainless steel used. With regard to the widespread practice of subcontracting within the cluster, the trend on joint action is less clear. There is evidence to suggest that some large firms are moving toward greater internalization of production as a way to reduce quality-related transaction costs. This practice has involved "in-house" subcontracting and has resulted in the emergence of first-tier suppliers with whom large firms have closer ties, not only for purposes of monitoring but also for quality upgrading. It remains to be seen how widespread this practice 
will become and the consequences it will have on subcontracting more widely within the cluster. For most medium and small firms, subcontracting remains a significant element of production organization. There are signs of greater cooperation in ties that SMEs have with their subcontractors. It is also apparent, however, that with the exception of the use of 'travel cards', there is little to suggest that such ties have technically improved. Quality concerns were an important feature of these relationships before the FDA's actions, yet there are no apparent signs to show a qualitative upgrading within such production linkages as a consequence of the new competition.

Greater cooperation with buyers emerges as statistically the most significant factor associated with firm growth, even when accounting for firm size. In some cases it is apparent that forward ties have weakened, due to price competition and reduction in unit prices that have been seen in the leading export markets, and as a consequence of certification itself. On the whole though, ties with external buyers have grown in importance in the cluster, particularly as conduits of information and new know-how. It is also apparent that they have led to a shift in the terms of trade in favor of buyers. Meanwhile horizontal joint action, particularly through the trade association, has been a key arena for strategic local cooperation and has generated cluster-wide advantages. The association helped connect local producers to external technical know-how at a critical juncture in the crisis, allowing SMEs to access knowledge that was prohibitively costly. The association also mobilized the state to intervene at this point.

Has the joint action that has occurred been wholly beneficial for the cluster or not? Sialkot's response to the FDA crisis provides clear signs of greater collective action as well as elements of what I term collective failure - that is to say, where collective action failed to take place, or where the actions of local agents led to a deterioration of their collective position.

The previous sections provide an account of how vertical and horizontal production and trade ties have changed since 1994 . In some cases these developments have also led to the emergence of further problems for the cluster, and there are other areas where the lack of joint action has meant that existing problems remain unresolved. These areas of collective failure include the inability of the cluster to address a number of collective problems that were present before the FDA crisis and which remain an issue: poor infrastructure, and sanitation, low safety and health standards and the continued use of child labor. Sialkot's other leading export cluster, the sports good industry, has seen the damaging effect the use of child labor can have on its global reputation and on its exports (Marcus and Harper, 1996; Save the Children Fund, 1997). Child labor is less of a problem in the surgical instrument sector but it does exist. SIMA has begun to work with its members to ensure that they do not use child labor. It has not, however, been able to change practices among subcontractors where some child labor can be found.

Another area where there remains a collective failure within the cluster is environmental costs of surgical instrument manufacturing. The GMP and ISO 9000 quality assurance requirements are only the first stage in an increasingly more stringent and quality-driven market environment. ISO 14000 requirements are likely to follow hard on the heels of the current quality-assurance demands. This will become another important area for the Sialkot cluster where joint action could lead to significant improvements in working conditions, health and safety standards, pollution control and overall improvement of the physical environment in which manufacturing takes place.

Similarly, the poor condition of local infrastructure - especially power supply, roads, and sewerage - act as an inhibiting factor on the cluster's potential growth. Again, local producers have not yet explored the possibility of joint action. All of these are issues that the cluster will have to address if it is to raise its productive efficiency and continue to meet the increasingly stringent standards that Western markets demand.

A particularly important aspect of collective failure, highlighted by the survey data on changes in horizontal and vertical ties, is the limited increase in inter-firm cooperation aimed at bringing about improvements in labor training. The cluster's skill base is traditional, and to some extent artisanal. It has been a key factor in generating the cluster's competitiveness. As the quality assurance crisis has indicated, however, the nature of markets are rapidly changing, calling for new skills and undermining the basis of traditional practices. In this rapidly changing environment, a failure to improve labor skills and to build the cluster's 
technical capacity does not bode well for its ability to upgrade in a sustained fashion.

On the specific and immediate issue of quality assurance, however, there was a significant increase in interfirm cooperation. This conclusion needs to be qualified. Once agents (and more broadly the cluster as a whole) are certified as meeting regulatory standards, transaction costs for external buyers engaging with local producers are effectively lowered. Standard certification assures that firms conform to international quality assurance requirements. Standards, therefore, provide a basis for what Zucker (1986) refers to as institutional trust. This can potentially allow for the existence of arms-length contracts between agents within the supply chain. The institutional trust encapsulated in GMP certification has for some buyers meant a return to armslength contracts with local producers. Such buyers could loosen their longstanding ties with local producers and search out cheaper alternative suppliers.

Nevertheless, ensuring that the cluster as a whole complies, and that local firms therefore obtain the benefits of this reputation effect, requires effective local governance and regulation. Cooperation of private actors is not sufficient and the state has a role to play here. In subsidizing the costs for local firms to obtain the know-how to get through the GMP hurdles, the state in coordination with the trade association provided the cluster's producers, particularly SMEs, with a way through the crisis.

Thus this study indicates a mixed story on the response of the Sialkot surgical instrument cluster to the crisis in quality assurance. There has been extensive local cooperation especially through a more invigorated trade body. Joint action in vertical ties is apparent, but uneven. Alongside examples of collective action there remains collective failure. The evidence suggests that a process of differentiation has resulted, with SMEs being squeezed while larger producers are better positioned to switch gears and become internationally certified in quality assurance. At the same time the more proactive stance of the trade body and its role in facilitating the provisioning of quality-related services to the cluster as whole has allowed many SMEs to upgrade and comply with GMP standards. What is of importance and at issue, however, is not so much the demise of smaller firms but the survival and continuing growth of the cluster as whole. Here there may be evidence that Sialkot's surgical instrument cluster may manage to rise to the challenge. Clearly the ability of the cluster to do so will rest in large measure on the issue of local governance. The type of governance determines the nature of inter-firm relations within vertical supply chains that link local suppliers and manufacturers to external markets, as well as the strength of horizontal relations that provide the basis for collective joint action within the cluster. The challenge for the Sialkot cluster is to address the collective failures pointed out above. The increasing differentiation makes it difficult to rely entirely on the cooperation of private actors to solve these problems. Public intervention in partnership with private initiative is required to sustain the cluster's competitiveness.

\section{NOTES}

1. On labor standards see, for example, Sengenberger and Campbell (1994), ILO (1997) and Lee (1997). On standards and global "value chains," see Brown et al. (1993). On ethical standards, see Zadek and Tiffen (1996) on fair trade initiatives, Hilowitz (1997) on social labeling and van Liemt (1998) and Murray (1997) on corporate codes of conduct.

2. The paper is based on research undertaken prior to the financial crisis that Pakistan faced in 1998 following the explosion of nuclear devices and, therefore, does not take into account the impact of these events on the cluster.
3. For reasons of confidentiality all firm and respondent names, where reported, have been altered.

4. The survey instrument was based on one developed jointly with Peter Knorringa, Roberta Rabellotti and Hubert Schmitz.

5. On the cluster's history see Nadvi (1996).

6. The consultant does not do the actual GMP certification. That is left to the FDA. Its task is simply to train management on GMP and TQM issues. This is done through day-long seminars, the dissemination of 
quality related literature, on-site training and pre-certification inspections.

\section{Source: SIMA and Federal Bureau of Statistics.}

8. It should be noted, however, that by December 1997 neither facility had been set up.

9. The index was generated by attaching equal weights to each of the specific relevant variables in each category of backward, forward and horizontal relationships. The five possible responses for each variable, from "big increase" to "big decrease" were coded on a range of +2 to -2 , with no change being coded as 0 . Variables that were seen to have been insignificant for this particular case study (such as speeding up delivery) were dropped from the analysis, while others that were unique to the Sialkot cluster (such as help in developing quality assurance systems) were included in the respective indices.

\section{REFERENCES}

Anderson, K. (1996) Environmental standards and international trade. Proceedings of the World Bank Annual Conference on Development Economics, 317 338.

Audretsch, D. and Feldman, M. (1996) R \& D spillovers and the geography of innovation and production. American Economic Review (June), 630-640.

Brown, H. S., Derr, P., Renn, O. and White, A. L. (1993) Corporate Environmentalism in a Global Economy. Quorum, Westport, CT.

Brusco, S. (1992) Small firms and the provision of real services. In Industrial Districts and Local Economic Regeneration, ed. F. Pyke and W. Sengenberger. International Institute of Labour Studies, Geneva.

Dion, C., Lanoie, P. and Laplante, B. (1997) Monitoring environmental standards: Do local conditions matter? World Bank Development Research Group Policy Research Working Paper No. 1701. World Bank, Washinton, DC, January.

Foss, N. J. (1996) Higher-order industrial capabilities and competitive advantage. Journal of Industry Studies 3(1), 1-20.

GEMCO Industrial Development (1990) Technology needs assessment (Draft). MIDC project, Unpublished manuscript, Sialkot, Pakistan.

Grootaert, C. and Kanbur, R. (1995) Child labour: An economic perspective. International Labour Review 134, 187-203.

Hilowitz, J. (1997) Social labeling to combat child labour: Some considerations. International Labour Review 136(2), 215-232.

ILO (1997) Child labour: How the challenge is being met prepared by Mark Lansky. International Labour Review 136(2), 233-257.

Kaplinsky, R. (1998) Globalisation, industrialisation and sustainable growth: The pursuit of the Nth rent. Discussion Paper No. 365, Institute of Development Studies, University of Sussex, Brighton.

Krueger, A. B. (1996) International labor standards and trade. Proceedings of the World Bank Annual Conference on Development Economics, 281-315.

Lee, E. (1997) Globalisation and labour standards: A review of issues. International Labour Review 136(2), 173-189.

van Liemt, G. (1998) The social policy implications of codes of conduct, with particular reference to the relations between companies adopting such codes and their suppliers and subcontractors. Paper presented at International workshop on Global Production and Local Jobs: New Perspectives on Enterprise Networks, Employment and Local Development Policy, International Institute of Labour Studies, Geneva, March 9-10.

Marcus, R. and Harper, C. (1996) Small hands: Children in the working world. Working Paper No. 16, Save the Children Fund, London.

Maskus, K. E. (1997) Should core labor standards be imposed through international trade policy? World Bank Development Research Group Policy Research Working Paper No. 1817, World Bank, Washington, DC, August.

Murray, J. (1997) Corporate codes of conduct and fair labour standards. Paper presented at International workshop on Global Production Systems and Labour Markets, International Institute of Labour Studies, Geneva, May 22-23.

Nadvi, K. M. (1996) Small Firm Industrial Districts in Pakistan. DPhil Thesis. University of Sussex.

Nadvi, K. (1999) The cutting edge: Collective efficiency and international competitiveness in Pakistan. $O x$ ford Development Studies 27(1), 81-107.

OECD (1996) Trade, Employment and Labour Standards: A Study of Core Workers' Rights and International Trade. OECD, Paris.

OECD (1995) Trade and Labour Standards: A Review of the Issues. Prepared by Gary Fields, OECD, Paris.

Sako, M. (1992) Prices, Quality and Trust. Cambridge University Press, Cambridge.

Save the Children Fund, (1997) Stitching Football: Voices of Children. Save the Children Fund, London.

Sengenberger, W. and D. Campbell, eds. (1994) International Labour Standards and Economic Interdependence. International Institute for Labour Studies, ILO, Geneva.

Sengenberger, W. and Pyke, R. (1991) Small firm industrial districts and local economic regeneration: Research and Policy issues. Lobour and Society 16(1).

Stephenson, S.M. (1997) Standards and conformity assessment as non-tariff barriers to trade. World Bank Development Research Group Policy Research Working Paper No. 1826, World Bank, Washington, DC, September. 
Wiegersma, S. (1989) Analysis of the quality scene in the Pakistan surgical instruments industry. Mission Report, Dutch Technical Aid Program, Islamabad.

White, B. (1996) Globalisation and the child labour problem. Journal of International Development 8(6), 829-839.
Zadek, S. and Tiffen, P. (1996) "Fair trade": Business or campaign? Development 3.

Zucker, L. G. (1986) Production of trust: Institutional sources of economic structure, 1840-1920. Research in Organisational Behaviour 8, 53-111. 